\title{
A Literature Review of Old Products Recycling and Trade-In
}

\author{
Huayi Li \\ School of Management, Jinan University, Guangzhou, China \\ Email: lihuayi1116@163.com
}

How to cite this paper: Li, H.Y. (2019) A Literature Review of Old Products Recycling and Trade-In. American Journal of Industrial and Business Management, 9, 1969-1979.

https://doi.org/10.4236/ajibm.2019.911128

Received: October 16, 2019

Accepted: November 5, 2019

Published: November 8, 2019

Copyright $\odot 2019$ by author(s) and Scientific Research Publishing Inc. This work is licensed under the Creative Commons Attribution International License (CC BY 4.0).

http://creativecommons.org/licenses/by/4.0/

(c) (i) Open Access

\begin{abstract}
As people's awareness of environmental protection increases. Therefore many researchers have paid attention to how to recycle and reuse the old products in the hands of consumers. Trade-in as one of the effective methods of recycling old products has also become the focus of researchers. In order to better understand the research progress of researchers on the old product recycling and trade-in, this paper has sorted out the relevant literature. After sorting out, it was found that researchers mostly study the recycling of old products from the choice of recycling methods, the impact of recycling of old products on pricing and multi-recycling channels. The main research method of this paper is to find out the shortcomings of the existing research through literature combing. The purpose of this research is to provide relevant inspiration and suggestions for future research, but also helping to find out the blank points of the research for further exploration; and helping to inspire recyclers to choose the optimal recycling strategy to better recycle old products, so as to achieve the utilization of resources.
\end{abstract}

\section{Keywords}

Old Products Recycling, Trade-In, Recycling Methods, Product Pricing

\section{Introduction}

With the increasing popularity of electronic products such as household appliances, digital products, the renewal is more and more frequent, and the "electronic waste" generated in life is also showing a trend of almost exponential growth. We have to face the huge impact of resource shortage and waste pollution on people's living environment. So how to recycle the old products in the hands of users has become a key issue for people. Among them, trade-in as one of the effective ways to recycle old products has attracted people's attention. In 
2009, the Chinese government implemented the trade-in subsidy policy for automobiles and household appliances, which attracted a large number of enterprises and consumers to participate in it and benefited from it. The speed of product renewal and the change of customer consumption concept also made the trade-in voices gradually higher. After the government subsidies, many enterprises are still implementing trade-in. It is not only a kind of behavior that allows the environment to continue to develop, but also a market behavior that stimulates demand and promotes product upgrading.

A large number of scholars have studied the old product recycling and trade-in. This research problem is: What is the current research progress on the recycling of old products and trade-in? What factors will affect the company's trade-in strategy? What factors will affect consumers' willingness to recycle old products and their willingness to trade-in? Research objective is that it not only helps to understand the research progress of the old product recycling and trade-in, but also helping to find out the blank points of the research for further exploration; and helping to inspire recyclers to choose the optimal recycling strategy to better recycle old products, so as to achieve the utilization of resources.

\section{Researches on the Recycling of Old Products}

The research on the recycling of old products mainly includes the following three aspects: 1) the choice of recycling methods; 2) the impact of recycling on product pricing mechanism; 3) multiple recycling channels.

\subsection{The Choice of Recycling Methods}

In the reverse supply chain, which kind of recycling method is the best choice has always been the focus of researchers. As the earliest group of researchers concerned about closed-loop supply chain, Savaskan et al. [1] first defined the important concepts of positive and negative supply chain, and thought that according to the different recycling subjects, the recycling modes of closed-loop supply chain can usually be divided into three types: manufacturer recycling, retailer recycling and third-party recycling. By comparing and analyzing these three situations, retailer recycling is most efficient in their recycling operations. Based on it, Atasu et al. [2] discussed the selection and arrangement of the best reverse recovery methods for remanufacturer considering the cost recovery factor, which indicated that the cost structure was an important factor affecting the choice of reverse recovery methods. Hong et al. [3] explored the situation that retailers are responsible for recycling waste products, and manufacturers entrust all recycled waste products from retailers to specialized third-party enterprises for processing, which proves the efficiency and economic rationality of the operation mode which includes division of labor and cooperation. Similarly, Webster et al. [4] analyzed how to make strategic choices in order to maximize the profits of manufacturers and remanufacturers when the process of product recycling 
and remanufacturing is charge by third parties. At the same time, many researchers have studied the impact of other factors on the choice of the optimal recycling mode. Jeffrey et al. [5] discussed it from the perspective of consumers and analyzed what kind of selection strategy that manufacturers and retailers should choose when consumers need to bear certain returns penalties. Similarly, Feng et al. [6] introduced the consumer preferences of online recycling channels into the selection of recycling methods, and examined the efficiency and supply chain coordination of two single recycling modes (retailer direct recycling and manufacturer online recycling) and two double recycling modes (manufacturer and retailer simultaneously responsible for recycling under centralized and decentralized decision-making).

Sun et al. [7] analyzed the optimal decision-making problem of supply chain members under three different recycling modes: two retailers recycling, one retailer recycling and one manufacturer recycling. By comparing the profit functions, it provided some reference for the selection of recycling modes from the manufacturer's point of view. Fu et al. [8] constructed a game model of dealer recycling mode selection under double-chain competition. Through the analysis and conclusion of the model, it provided theoretical support and guidance for real-life processor decision-making. By constructing a forward and reverse supply chain model with mixed recycling, Yi and Liang et al. [9] analyzed the pricing of goods and the profit of supply chain under three different recycling modes: the case of co-recycling by retailers and manufacturers, the case of co-recycling by manufacturers and third parties, and the case of co-recycling by third parties and retailers. Finally, the impact of rewards and penalties on decision-making and profit of enterprises was analyzed.

\subsection{The Impact of Recycling on Product Pricing Mechanism}

A large number of studies have shown that different recycling methods may have different effects on the operating performance and pricing strategy of closed-loop supply chain.

Han et al. [10] considered the risk factors in the process of remanufacturing and explored the pricing decision models of closed-loop supply chain under different recycling modes. The results showed that retailer recycling will be more profitable than the direct recycling by manufacturer. When recycled directly by the manufacturer, there is a greater risk of supply chain disruption, which will result in higher profits for the manufacturer. He et al. [11] respectively explored the closed-loop supply chain pricing model under cooperative and non-cooperative situations in the supply chain, aimed at recovery rate, remanufacturing rate, remanufacturing cost and remanufactured product price. The results showed that under the decentralized recycling structure, the optimal purchase price is always lower than the optimal purchase price under the centralized recycling structure, which leads to the reduction of recycling and the reduction of the number of remanufactured products. At the same time, the cost difference between the two 
recovery methods will also affect the pricing mechanism in the supply chain. Hong et al. [3] further explored the pricing mechanism of closed-loop supply chain under three mixed dual-channel recycling modes and compared their operational efficiency. Firstly, the manufacturer and the retailer recycle the old products at the same time. Secondly, the manufacturer gives the second-hand products back to the retailer and the third party. Thirdly, the manufacturer and the third party recycle the old products at the same time. By establishing a game model, the results showed that the other conditions remain unchanged. The mixed recycling mode of manufacturer and retailer is the most effective recycling mode for the manufacturer, in this mode, manufacturers have the best product pricing and profits. Zheng [12] explored the decentralized and centralized decision-making models of closed-loop supply chains with different market dominant forces, considering that manufacturers and retailers recycle waste products at the same time, and found that different powers have different effects on pricing strategies of closed-loop supply chains.

Guo et al. [13] considered that there is a difference in willingness to pay for new products and remanufactured products, discussed the optimal pricing strategy and recycling mode selection of closed-loop supply chain. The study conducted a comparative analysis of the manufacturer's choice of recycling models, taking into account the profit of manufacturer, product recovery rate and retail price. Zhang et al. [14] In view of the difference in sales price between new products and remanufactured products and the two recycling modes of waste products, the recycling and sales pricing strategies of closed-loop supply chain system are studied. The results showed that Stackelberg game pricing will result in the loss of system efficiency, while joint decision pricing can recover more waste products, the lowest price of products, and the maximum profit of the system.

\subsection{Multiple Recycling Channels}

In reality, it is impossible to have only one kind of recycling channel, and often several kinds of recycling channels coexist, and there is a cooperative and competitive relationship between them. A few scholars have considered the problem of coexistence of several recycling channels.

The researches on dual-channel recycling mainly focus on the impact of pricing strategies. Huang [15] studied and analyzed the impact of third-party recycling on profits and recovery rate of dual-channel closed-loop supply chain from a fair perspective and gave the evaluation criteria of supply chain performance. Ma et al. [16] studied the influence of government consumption subsidy on dual-channel closed-loop supply chain, analyzed the channel member strategies before and after the government-funded program, and analyzed consumer subsidies from the perspective of consumers, closed-loop supply chain scale and enterprises. Xie et al. [17] studied contract coordination under the centralized and decentralized decision-making in the dual-channel closed-loop supply chain. 
The relationship between recovery rate and recovery rate of return was considered. It was shown that the recovery rate of waste products was affected by reverse revenue-sharing ratio, and all optimal prices decreased with the revenue-sharing ratio. At the same time, scholars considered consumer preferences for remanufactured products and their willingness to recycle used products. Gan [18] considered consumer acceptance of remanufactured products and the impact of consumer preferences for direct sale channels on pricing and profits of closed-loop supply chain. Heydari [19] considered the impact of offering discounts or cash on consumers' willingness to provide used products. Kumar [20] studied cooperation and competition in closed-loop supply chain. The supply chain consists of two manufacturers. In view of three different cases: non-cooperation, partial cooperation and complete cooperation, game models were established respectively, and the optimal wholesale price and retail price were obtained to provide reference for practice.

In the study of mixed recycling channels, researchers mostly studied from two aspects: competition of mixed recycling channels and competition of recycling channels and sales channels. In terms of competition in mixed recycling channels, Huang [15] studied the decision-making problem of closed-loop supply chain with mixed recycling channels, and compared it with the optimal decision-making of closed-loop supply chain with only one recycling channel, and found that the choice of the optimal recycling channel depends on the competition intensity. Hong et al. [3] studied the problem of selecting the optimal recycling mode for closed-loop supply chain with three reverse mixed recycling channels and designed a structural model to obtain the most favorable recycling channel structure for manufacturers. In terms of competition between recycling channels and sales channels, some scholars have studied that two retailers compete simultaneously in the process of new product sales and old product recycling. Xie [21] found that the more intense the competition between the two retailers in the process of recycling, the profits of manufacturers and retailers in both positive and reverse channels will be lost. Zhu et al. [22] considered the cost and remanufacturing ratio between offline recycling and online recycling channels, a Stackelberg game pricing model between manufacturers, distributors and online recyclers is constructed. The optimal recycling pricing and profit of dual channels under decentralized decision-making and centralized decision-making indicate that the profit level of the entire closed-loop supply chain is highest under centralized decision-making, and the problem of double marginalization under decentralized decision-making leads to efficiency loss. Zhang [14] analyzed the optimal product price and recovery price strategy based on the difference in the price of remanufactured products and the recycling channels of various old products. Based on a multi-channel recycling mechanism, the revenue sharing mechanism is used to achieve supply chain coordination. Wang [23] studied the closed-loop supply chain with dual-channel recycling mechanism, gave the optimal strategy analytic formula of different decision-making modes, 
and discussed the influence of factors such as government intervention and joint decision-making on the optimal strategy. The result shows that collaborative decision-making model of government interference is an ideal closed-loop supply chain management and given the appropriate path to achieve. The realization of the desired management mode requires both an effective coordination mechanism and an effective government incentive mechanism. Yi and Yuan [24] established a remanufacturing closed-loop supply chain model under mixed recycling and analyzed the impact of competition and conflict caused by hybrid recycling on node enterprise pricing decisions and profits.

\section{Relevant Research on Trade-In Activities}

At present, many researchers have studied the trade-in from many angles. According to the collation of existing literature, it can be mainly divided into: 1) the willingness of consumers to participate in trade-in, and 2) the price of trade-in

\subsection{The Willingness of Consumers to Participate in Trade-In Activities}

In the research on trade-in from the perspective of consumers, more scholars pay attention to the willingness of consumers to pay in the trade-in activities. It is generally believed that when consumers have higher willingness to pay, they are more motivated to participate in trade-in.

Klemperer [25] proposed that trade-in service would increase the cost of converting consumers, so companies offering trade-in activities would reduce consumers' willingness to change enterprises. In other words, when enterprises provide trade-in service, they can often increase the loyalty of consumers, which can explain why many enterprises are willing to provide trade-in service to increase consumers' willingness to buy and frequency of purchase. Zhu [26] focused on the psychology of consumers, and found that consumers who are willing to participate in trade-in are more willing to pay for products than those who only buy new products. They are more concerned about the value of old products. Therefore, they are often more willing to participate in trade-in activities. However, Kim et al. [27] found different conclusions. and found that when the price of old products is lower than the price of new products, the consumer's willingness to pay will be lower, because consumers often think that lower prices of remanufactured product may be defective in quality. Yin [28] studied the optimal purchase decision of consumers between current products and next generation products in the pre-paid trade-in model and found that enterprises can always obtain higher profits by offering trade-in service.

\subsection{Research on Discount and Pricing of Trade-In Activities}

There are also some literature studies that provide discounts and pricing issues when providing trade-in services. Yin [28] constructed a two-stage dynamic 
game model for trade-in service. Based on the analysis of consumers purchase behavior, the optimal pricing strategies of the two-generation products were further studied, and it was found that the trade-in model is always more conducive to enterprises with more deterministic conditions. Yin [29] pointed out that in order to attract consumers to buy current and next-generation products, many manufacturers and retailers offer discount pricing schemes that allow buyers of first-generation products to buy products at lower prices and buy new-generation products. By considering the interaction between "forwardlooking" consumers and enterprises and the heterogeneity of market consumers, we found that forward-looking consumers are willing to pay higher prices than the value of products. Chen [30] further proposed that when considering strategic consumers, whether enterprises would carry out the trade-in depends on the price and characteristics of the new product, and proposed that the depreciation rate will increase with the increase of the depreciation rate of the used product, but decreases with the increase of consumer's willingness to exchange the old for the new products.

Agrawal [31] studied the impact of trade-in preferences on price discrimination, established a bargaining model between manufacturers and recyclers, and finally coordinated the price issue between them by providing trade-in services, and proposed that an enterprise can achieve perfect price discrimination by using trade-in preferences. Ray [32] studied how firms can provide optimal service strategies to replace old products with new ones under the assumption that durable goods technology is relatively stable. They found that changes in trade-in rebate were affected by factors such as the durability and depreciation rate of used products. Research indicated that consumers can get trade-in rebate from the business by submitting a waste product discount. This discount can be regarded as a kind of price discrimination for future purchases. Chen [33] explored the opportunities and ways for enterprises to offer discounts on trade-in. In order to achieve better price discrimination and weaken competition from third-party remanufacturers, and proposed that the discount on trade-in increases with the depreciation rate of used products, but decreases with the increase of consumer's willingness to replace old products with new ones.

There are also some studies that analyze how companies should choose between trade-in strategies and single-price strategies, and the impact of trade-in on closed-loop supply chains when the proportion of new and old consumers is different. Zhu et al. [34] also analyzed the multi-monopoly competition in the trade-in method with government subsidies based on the analysis of consumer purchasing behavior and found that government subsidies do not always effectively improve the old products recycling. Liu et al. [35] studied the problem of trade-in and pricing equilibrium faced by duopoly competitors who enter the market successively and analyzed the impact of the existence of competition on the trade-in strategy. Wu et al. [36] found that the trade-in strategy affects the sales and profit of the enterprise by comparing the trade-in strategy with the 
single-price strategy and analyzed the impact of factors such as the cost structure and the proportion of consumers on the enterprise, indicating that enterprises can make corresponding decisions according to different conditions. Ma and Zhao [37] studied the effects of government subsidy on centralized decision-making, manufacturer-retailer cooperation, manufacturer-recycler cooperation and decentralized decision-making on the pricing decisions of four models. Getting the government trade-in subsidy is conducive to the increase of the scale of closed-loop supply chain and environmental protection.

\section{Findings}

Based on the review of the existing literature on the old product recycling and the trade in, this paper finds that:

1) Recycling methods are mainly divided into manufacturer recycling, retailer recycling and third-party recycling. Scholars have considered the impact of different factors on the choice of optimal recycling methods from different perspectives, mostly focusing on factors such as recycling costs, consumer preferences. When considering different supply chain structures, there are different optimal selection strategies from the perspective of manufacturers and retailers when there exists third-party recycling.

2) Different recycling methods will have an impact on product pricing, and more consideration will be given to the impact of different recycling methods on the recycling pricing of old products and the pricing of remanufactured products. Researchers always analyze the optimal pricing strategies of manufacturers and retailers from the perspective of single pricing and differential pricing. At the same time, when considering the existence of multiple recycling channels, factors such as government subsidies and channel competition in the recycling channels will have an impact on corporate profits.

3) Trade-in is one of the effective ways to recycle old products. The willingness of consumers to participate in trade-in is the focus of scholars' research. The research found that consumers who participate in trade-in have higher willingness to pay, because they often have a higher awareness of environmental protection.

4) Regarding the researches on discounts and pricing in trade-in, the enterprises should consider how to provide the best rebate to attract consumers to participate in the process of trade-in. The results show that recycling costs, consumer awareness of environmental protection and surplus value of the old products are all important factors affecting the preferential policy of trade-in. Some scholars have studied how retailers should set prices to maximize profits under monopoly and competition when there is a trade-in.

\section{Conclusions}

Researchers mostly study the recycling of old products from the choice of recycling methods, the impact of recycling of old products on pricing and mul- 
ti-recycling channels. Government subsidies, recycling cost, consumer awareness of environmental protection, channel competition and other factors are important factors discussed by researchers. However, the research on trade-in is mostly focused on consumers' willingness to participate in trade-in, preferential policies and product pricing strategies.

Although the current researches have achieved some important results, there are still some problems worthy of further exploration: 1) At present, there is no research on the e-commerce platform to carry out the trade-in. When the e-commerce platform carries out the trade-in, how will it affect product pricing in closed-loop supply chain? How much effort should the platform make in retrieving old products? 2) E-commerce platform also has different recycling modes when it comes to trade-in. Existing studies have not considered the choice of recycling modes when E-commerce platform implements the trade-in. 3) In the existing trade-in activities, coupons are often offered to attract consumers. How do different types of coupons affect the demand for trade-in and the profits of the whole supply chain? These are all issues worth studying in the future.

\section{Conflicts of Interest}

The author declares no conflicts of interest regarding the publication of this paper.

\section{References}

[1] Savaskan, R.C., Bhattacharya, S. and Van Wassenhove, L.N. (2004) Closed-Loop Supply Chain Models with Product Remanufacturing. Management Science, 50, 239-252. Https://doi.org/10.1287/Mnsc.1030.0186

[2] Atasu, A., Toktay, L.B. and Van Wassenhove, L.N. (2013) How Collection Cost Structure Drives a Manufacturer's Reverse Channel Choice. Production and Operations Management, 22, 1089-1102. https://doi.org/10.1111/j.1937-5956.2012.01426.x

[3] Hong, X., Wang, Z., Wang, D. and Zhang, H. (2013) Decision Models of Closed-Loop Supply Chain with Remanufacturing under Hybrid Dual-Channel Collection. The International Journal of Advanced Manufacturing Technology, 68, 1851-1865. https://doi.org/10.1007/s00170-013-4982-1

[4] Webster, S. and Mitra, S. (2007) Competitive Strategy in Remanufacturing and the Impact of Take-Back Laws. Journal of Operations Management, 25, 1123-1140. https://doi.org/10.1016/j.jom.2007.01.014

[5] Shulman, J.D., Coughlan, A.T. and Savaskan, R.C. (2010) Optimal Reverse Channel Structure for Consumer Product Returns. Marketing Science, 29, 1071-1085. https://doi.org/10.1287/mksc.1100.0578

[6] Feng, L., Govindan, K. and Li, C. (2017) Strategic Planning: Design and Coordination for Dual-Recycling Channel Reverse Supply Chain Considering Consumer Behavior. European Journal of Operational Research, 260, 601-612. https://doi.org/10.1016/j.ejor.2016.12.050

[7] Sun, J.Y. Teng, C.X. and Chen, Z.B. (2013) Channel Selection Model of Remanufacturing Closed-Loop Supply Chain Based on Recovery Price and Sales Quantity. System Engineering Theory and Practice, 33, 3079-3086. 
[8] Fu, X.Y., Zhu, Q.H. and Zhao, T.L. (2014) Selection of the Recovery Channel Based on Recovery Price Competition between the Reverse Supply Chains. Chinese Journal of Management Science, 22, 72-79.

[9] Yi, Y.-Y. and Liang, J.M. (2014) Hybrid Recycling Modes for Closed-Loop Supply Chain under Premium and Penalty Mechanism. Computer Integrated Manufacturing System, 20, 215-223.

[10] Han, X., Wu, H., Yang, Q. and Shang, J. (2017) Collection Channel and Production Decisions in a Closed-Loop Supply Chain with Remanufacturing Cost Disruption. International Journal of Production Research, 55, 1147-1167. https://doi.org/10.1080/00207543.2016.1230684

[11] He, Y. (2015) Acquisition Pricing and Remanufacturing Decisions in a Closed-Loop Supply Chain. International Journal of Production Economics, 163, 48-60. https://doi.org/10.1016/j.ijpe.2015.02.002

[12] Zheng, B., Yang, C., Yang, J. and Zhang, M. (2017) Dual Channel Closed Loop Supply Chains: Forward Channel Competition, Power Structures and Coordination. International Journal of Production Research, 55, 3510-3527. https://doi.org/10.1080/00207543.2017.1304662

[13] Guo, J.H., Li, B.Y. and Ni, M. (2015) The Selection of Take-Back Model of Remanufacturing Closed-Loop Supply Chain Based on WTP Differentiation. Chinese Journal of Management, 12, 142.

[14] Zhang, C.T. and Yang, S.L. (2013) Pricing and Coordination Strategy of Closed-Loop Supply Chain under Dual Channel Recovery. Computer Integrated Manufacturing System, 19, 1676-1683.

[15] Huang, M., Song, M., Lee, L.H. and Ching, W.K. (2013) Analysis for Strategy of Closed-Loop Supply Chain with Dual Recycling Channel. International Journal of Production Economics, 144, 510-520. https://doi.org/10.1016/j.ijpe.2013.04.002

[16] Ma, W.M., Zhao, Z. and Ke, H. (2013) Dual-Channel Closed-Loop Supply Chain with Government Consumption-Subsidy. European Journal of Operational Research, 226, 221-227. https://doi.org/10.1016/j.ejor.2012.10.033

[17] Xie, J., Liang, L., Liu, L. and Ieromonachou, P. (2017) Coordination Contracts of Dual-Channel with Cooperation Advertising in Closed-Loop Supply Chains. International Journal of Production Economics, 183, 528-538. https://doi.org/10.1016/j.ijpe.2016.07.026

[18] Gan, S.S., Pujawan, I.N. and Widodo, B. (2017) Pricing Decision for New and Remanufactured Product in a Closed-Loop Supply Chain with Separate Sales-Channel. International Journal of Production Economics, 190, 120-132. https://doi.org/10.1016/j.ijpe.2016.08.016

[19] Heydari, J., Govindan, K. and Jafari, A. (2017) Reverse and Closed Loop Supply Chain Coordination by Considering Government Role. Transportation Research Part D: Transport and Environment, 52, 379-398. https://doi.org/10.1016/j.trd.2017.03.008

[20] Jena, S.K. and Sarmah, S.P. (2014) Price Competition and Co-Operation in a Duopoly Closed-Loop Supply Chain. International Journal of Production Economics, 156, 346-360. https://doi.org/10.1016/j.ijpe.2014.06.018

[21] Xie, J., Zhang, W., Liang, L., Xia, Y., Yin, J. and Yang, G. (2018) The Revenue and Cost Sharing Contract of Pricing and Servicing Policies in a Dual-Channel Closed-Loop Supply Chain. Journal of Cleaner Production, 191, 361-383. https://doi.org/10.1016/j.jclepro.2018.04.223

[22] Zhu, X.D., Wu, B.B. and Wang, Z. (2018) Closed-Loop Supply Chain Pricing Strat- 
egy and Coordination Mechanism under the Difference of Dual-Channel Recovery Cost. Chinese Journal of Management Science, 25, 188-196.

[23] Wang, Y.Y. (2012) The Closed-Loop Supply Chain Models Analysis Based on Dual Channel Taking-Back under Government Intervention. Operations Research and Management Science, 21, 250-255.

[24] Yi, Y.-Y. and Yuan, J. (2011) Pricing Coordination in Closed-Loop Supply Chain with Hybrid Recovery Channel. Management Review, 23, 169-176.

[25] Klemperer, P. (1987) Markets with Consumer Switching Costs. The Quarterly Journal of Economics, 102, 375-394. https://doi.org/10.2307/1885068

[26] Zhu, R.J., Chen, X.J. and Dasgupta, S. (2008) Can Trade-Ins Hurt You? Exploring the Effect of a Trade-in on Consumers' Willingness to Pay for a New Product. Journal of Marketing Research, 45, 159-170. https://doi.org/10.1509/jmkr.45.2.159

[27] Kim, J., Rao, R.S., Kim, K. and Rao, A.R. (2011) More or Less: A Model and Empirical Evidence on Preferences for under-and Overpayment in Trade-in Transactions. Journal of Marketing Research, 48, 157-171. https://doi.org/10.1509/jmkr.48.1.157

[28] Yin, R. and Tang, C.S. (2014) Optimal Temporal Customer Purchasing Decisions under Trade-in Programs with up-Front Fees. Decision Sciences, 45, 373-400. https://doi.org/10.1111/deci.12081

[29] Yin, R., Li, H. and Tang, C.S. (2015) Optimal Pricing of Two Successive-Generation Products with Trade-in Options under Uncertainty. Decision Sciences, 46, 565-595. https://doi.org/10.1111/deci.12139

[30] Chen, J.M. and Hsu, Y.T. (2015) Trade-ins Strategy for a Durable Goods Firm Facing Strategic Consumers. International Journal of Industrial Engineering, 22, 183-194.

[31] Agrawal, V.V., Ferguson, M. and Souza, G.C. (2016) Trade-in Rebates for Price Discrimination and Product Recovery. IEEE Transactions on Engineering Management, 63, 326-339. https://doi.org/10.1109/TEM.2016.2574244

[32] Ray, S., Boyaci, T. and Aras, N. (2005) Optimal Prices and Trade-in Rebates for Durable, Remanufacturable Products. Manufacturing \& Service Operations Management, 7, 208-228. https://doi.org/10.1080/21681015.2015.1071288

[33] Chen, J.M. and Hsu, Y.T. (2015) Trade-in Strategy for a Durable Goods Firm with Recovery Cost. Journal of Industrial and Production Engineering, 32, 396-407.

[34] Zhu, X., Wang, M., Chen, G. and Chen, X. (2016) The Effect of Implementing Trade-in Strategy on Duopoly Competition. European Journal of Operational Research, 248, 856-868. https://doi.org/10.1016/j.ejor.2015.07.053

[35] Liu, L.C. and Zhai, X. (2018) Trade-in Strategy in Competitive Market. Chinese Journal of Management Science, No. 9, 8.

[36] Wu, P. (2014) Optimal Pricing Strategies for the Adoption of a Trade-in Scheme. System Engineering Theory and Practice, 34, 1188-1195.

[37] Ma, W.M. and Zhao, Z. (2012) Different Models of Closed-Loop Supply Chain with the Government Replacement-Subsidy. System Engineering Theory and Practice, 32, 1938-1944. 